\title{
Fully Synthetic Heparan Sulfate-Based Neural Tissue Construct That Maintains the Undifferentiated State of Neural Stem Cells
}

\author{
Pradeep Chopra ${ }^{\dagger}$, Meghan T. Logun ${ }^{\ddagger}$, Evan M. White ${ }^{\S}$, Weigang Lu ${ }^{\dagger, \|}$, Jason Locklin ${ }^{\S}$, , \\ Lohitash Karumbaiah ${ }^{*} \neq$, Geert-Jan Boons ${ }^{*}, \dagger, \|, \perp$ \\ † Complex Carbohydrate Research Center, University of Georgia, 315 Riverbend Road, Athens, \\ Georgia 30602, United States ₹ Regenerative Bioscience Center, ADS Complex, University of \\ Georgia, 422 River Road, Athens, Georgia 30602, United States $\S$ New Material Institute, \\ University of Georgia, 220 Riverbend Road, Athens, Georgia 30602, United States "Department \\ of Chemistry, University of Georgia, 140 Cedar Street, Athens, Georgia 30602, United States ${ }^{\perp}$ \\ Department of Chemical Biology and Drug Discovery, Utrecht Institute for Pharmaceutical \\ Sciences, and Bijvoet Center for Biomolecular Research, Utrecht University, Universiteitsweg 99, \\ 3584 CG Utrecht, The Netherlands
}

\begin{abstract}
Heparin and heparan sulfate (HS) are attractive components for constructing biomaterials due to their ability to recruit and regulate the activity of growth factors. The structural and functional heterogeneity of naturally derived heparin and HS is, however, an impediment for the preparation of biomaterials for regenerative medicine. To address this problem, we have prepared hydrogels modified by well-defined synthetic HS-derived disaccharides. Human induced pluripotent cellderived neural stem cells (HIP-NSCs) encapsulated in a polyethylene glycol-based hydrogel modified by a pendent HS disaccharide that is a known ligand for fibroblast growth factor-2 (FGF-2) exhibited a significant increase in proliferation and self-renewal. This observation is important because evidence is emerging that undifferentiated stems cells can yield significant therapeutic benefits via their paracrine signaling mechanisms. Our data indicate that the HS disaccharide protects FGF-2, which has a very short biological half-live, from degradation. It is anticipated that, by careful selection of a synthetic HS oligosaccharide, it will be possible to control retention and release of specific growth factor, which in turn will provide control over cell fate.
\end{abstract}

\section{Graphical Abstract}

\footnotetext{
*Corresponding Authors: gjboons@ccrc.uga.edu or g.j.p.h.boons@uu.nl. lohitash@uga.edu.

The authors declare no competing financial interest.

ASSOCIATED CONTENT

Supporting Information

The Supporting Information is available free of charge on the ACS Publications website at DOI: 10.1021/acschembio.9b00401. Full experimental details, characterization and spectral data of the compounds, hydrogel swelling data, 2D culturing of NSCs, and immunocytochemical results for Sox-1 (PDF)
} 


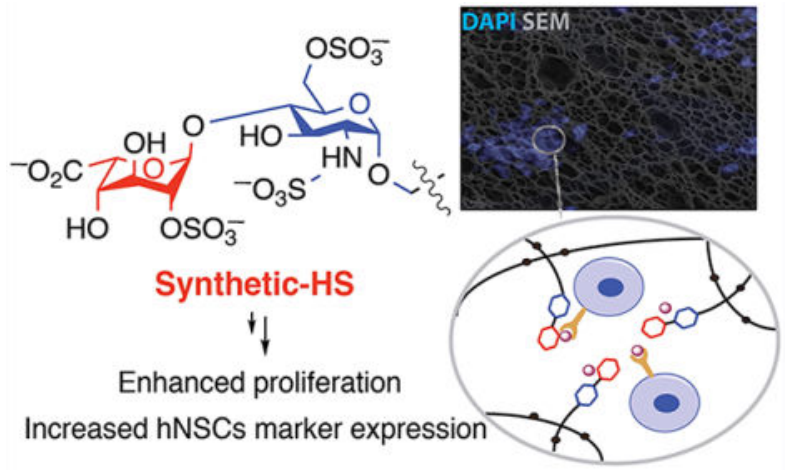

Hydrogels, which are formed by chemical or physical cross-linking of water-soluble polymers, provide attractive scaffolds for tissue regrowth and regeneration. ${ }^{1-3}$ The bulk properties of hydrogels can influence stem cell fate, and in particular, mechanical properties and chemical entities such as cell adhesion peptides have been explored to influence proliferation and differentiation. ${ }^{4}$ Glycosaminoglycans, such as heparin and heparan sulfate (HS), are also attracting considerable interest for the development of hydrogels for regenerative medicine. ${ }^{5}$

HS are highly sulfated linear polysaccharides that are ubiquitously expressed within the stem cell microenvironment or niche where they interact with numerous signaling proteins, growth factors, and extracellular matrix components. ${ }^{6,7}$ The biosynthesis of HS occurs in the Golgi by initially forming a linear polymer composed of alternating D-glucuronic acid (GlcA) and $N$-acetyl-D-glucosamine (GlcNAc) moieties, which are modified by a series of enzymatic transformations involving $N$-deacetylation $/ N$-sulfation, epimerization of GlcA to L-iduronic acid (IdoA), and sulfation of the C-2 hydroxyl of IdoA and the C-6 hydroxyl of glucosamine. These transformations proceed only partially, resulting in as many as 20 different disaccharide moieties that can be arranged in different ways to create specific HS epitopes. ${ }^{8}$

Evidence is emerging that cells can create unique HS epitopes by regulating the expression of isoforms of HS biosynthetic enzymes. ${ }^{9,10}$ The so-called "HS sulfate code hypothesis" is based on the notion that such epitopes can recruit or retain specific HS-binding proteins. Indeed, the structure of HS changes during stem cell differentiation, ${ }^{11}$ which in turn is important for the stage dependent recruitment of morphogens such as the fibroblast growth factors (FGFs), bone morphogenetic protein (BMP), and wingless-type MMTV integration site family proteins (Wnts). ${ }^{12}$

Polymeric matrixes modified by heparin or heparan sulfate offer interesting vehicles for the controlled delivery of growth factors. ${ }^{13}$ For example, the use of collagen modified by heparin in combination with recombinant fibroblast growth factor-2 (FGF-2) and vascular endothelial growth factor (VEGF) provided sustained release, induced vascularization, and reduced hypoxic conditions. ${ }^{14}$ In other studies, it has been found that functionalization of hyaluronic acid-based hydrogels with heparin diminished the burst release of BMP-2 and prolonged osteogenic activity. ${ }^{15}$ Despite these promising results, many challenges remain for the use of heparin or HS for biomaterial construction. In particular, the structural and 
functional complexity of these biopolymers is an impediment because it can cause adverse effects due to binding of many different proteins. ${ }^{16}$ In an interesting approach, this problem was addressed by using partial desulfated heparin, which could modify growth factor presentation and influence cell fate in a PEG-based hydrogel. ${ }^{17}$ In another study, affinity purification was employed to obtain an HS fraction that bound potently to BMP-2, greatly enhances BMP-2-induced bone formation in vitro and in vivo, and was much more efficacious than mucosal HS or heparin. ${ }^{18}$ These approaches are promising but still offer limited capabilities to control the binding properties of HS.

Recent progress in the chemical ${ }^{19}$ and chemoenzymatic ${ }^{20}$ synthesis of HS oligosaccharides is making it possible to probe ligand requirements of HS binding proteins. These studies reveal that relatively small structures, such as di- and tetra-saccharides, can bind with high affinity and selectivity to HS-binding proteins. ${ }^{21-23}$ Furthermore, the attachment of such compounds to polymeric backbones can provide neoglycopolymers that recapitulate properties of HS. ${ }^{24-27}$ Therefore, we were compelled to investigate whether small synthetic HS oligosaccharides can be employed for hydrogel formation to influence cell fate.

In a proof-of-principle study, we have synthesized a HS disaccharide that is a known ligand of FGF-2 $2^{28}$ and used it to fabricate a neural tissue mimic that can encapsulate, recruit, and maintain the undifferentiated state of neural stem cells (NSCs). These findings are important because NSCs have tremendous therapeutic potential to treat neurological deficits that manifest after injury or disease of the central nervous system (CNS). Although the focus on promoting the neuronal differentiation of NSCs to facilitate functional repair of neurological deficits has its merits, emerging evidence suggests that NSCs in their undifferentiated state promote more favorable functional outcomes via their paracrine signaling mechanisms rather than through differentiation and cell replacement per se. ${ }^{29}$ It is therefore plausible that strategies to promote "bystander" signaling by undifferentiated NSCs could carry a significant therapeutic benefit.

\section{RESULTS AND DISCUSSION}

\section{Chemical Synthesis}

Conventional approaches to incorporate heparin into biomaterial scaffolds rely on modification of the saccharide backbone with a reactive functional group. ${ }^{30,31}$ Such an approach is unsuitable for presenting small synthetic oligosaccharides because vital functional groups would be destroyed. Therefore, we developed a so-called pendant approach in which synthetic HS oligosaccharides (e.g., 10 and 11, Scheme 1) are modified with an artificial anomeric aminopentyl linker, which can react with an NHS activated triazide PEG linker such as $\mathbf{1 2}$ to yield HS oligosaccharides that possess three azide moieties (e.g., 13 and 14). It was anticipated that these azide-modified compounds could be crosslinked with a 4-armed PEG derivative modified with dibenzylcyclooctynol (17, DIBO) to yield stable hydrogels. ${ }^{32}$ This approach would appropriately place the HS disaccharides in the hydrogel lattice to facilitate functional interactions with HS-binding proteins. For the purpose of this study, compound $\mathbf{1 4}$ was selected as a high affinity ligand of FGF-2 28 whereas compound $\mathbf{1 3}$, which is devoid of sulfate groups, was used as a negative control. We anticipated that a hydrogel modified with a FGF-2 binding HS oligosaccharide will retain 
and stabilize this growth factor, which in turn would promote NSCs self-renewal and maintenance.

Functionalized HS disaccharides $\mathbf{1 3}$ and $\mathbf{1 4}$ were assembled from glycosyl acceptor $\mathbf{1}$ and idosyl donor $\mathbf{2}$, which were coupled using NIS/TMSOTf as the promoter system to give disacharide $\mathbf{3}$ in good yield as only the $\boldsymbol{a}$-anomer (Scheme 1A). ${ }^{33}$ The benzylidene acetal of 3 was removed by a mixture of trifluoroacetic acid, dichloromethane, and water to give a diol, which was subjected to TEMPO/BAIB to selectively oxidize the primary alcohol to a carboxylic acid, which was esterified by treatment with diazomethane to yield methyl ester 4. The $\mathrm{C}-4^{\prime}$ hydroxyl of $\mathbf{4}$ was protected as Fmoc by treatment with $\mathrm{FmocCl}$ in pyridine in the presence of a catalytic amount of DMAP to give disaccharide 5. Next, the levulinoyl (Lev) esters of $\mathbf{5}$ were removed by treatment with hydrazine acetate, and the resulting hydroxyls were sulfated using sulfur trioxide/pyridine complex in DMF, followed by Fmoc removal to provide 7. The methyl ester of 7 was saponified with $\mathrm{H}_{2} \mathrm{O}_{2}$ and $\mathrm{LiOH}$ in THF. The azide of the resulting compounds was reduced under Staudinger conditions using $\mathrm{PMe}_{3}$, and the resulting amine was $\mathrm{N}$-sulfated, employing a sulfur trioxide/pyridine complex in $\mathrm{MeOH}$ in the presence of $\mathrm{Et}_{3} \mathrm{~N}$ and $\mathrm{NaOH}$ to provide 9.

In parallel, disaccharide $\mathbf{4}$ was subjected to a similar sequence of reactions without $O$ sulfation and $\mathrm{N}$-acetylation instead of $\mathrm{N}$-sulfation to provide $\mathbf{8}$. The target disaccharides $\mathbf{1 0}$ and $\mathbf{1 1}$ were obtained by hydrogenation of $\mathbf{8}$ and $\mathbf{9}$, respectively, over $\mathrm{Pd} / \mathrm{C}$ in a mixture of $t \mathrm{BuOH} / \mathrm{H}_{2} \mathrm{O}(1 / 1)$ to cleave the protecting group of the linker followed by further hydrogenation over $\mathrm{Pd}(\mathrm{OH}) 2 / \mathrm{C}$ to remove the benzyl ethers, and finally purification by size exclusion chromatography over a P-2 column. Treatment of the latter compounds with the NHS activated triazide PEG linker 12 (Supplementary Scheme 1$)^{34}$ resulted in the formation of the desired derivatives 13 and 14, respectively. The DIBO-functionalized 4-armed PEG 17 was synthesized (Scheme 1B) by reaction of $p$-nitrophenyl carbonate of DIBO (16) with commercially available PEG tetra-amine $(\mathbf{1 5}, 10 \mathrm{kDa})$.

\section{Preparation and Characterization of HS-Containing Hydrogels}

Stoichiometric quantities of DIBO-functionalized 4-armed PEG 17 and triazidefunctionalized sulfated-HS disaccharide 14 (1:1 molar ratio of azide and DIBO) were mixed, resulting in the formation of stable hydrogels within $20 \mathrm{~min}$. The absence of the $\mathrm{N}_{3}$ stretch vibration at $2095 \mathrm{~cm}^{-1}$ in the IR spectra of the lyophilized sulfated-HS hydrogels indicated that the cycloaddition had proceeded to completion (Figure 1A). By varying the concentration of the components, the storage modulus of the sulfated-HS hydrogels could be tuned to match the material properties of the physiological host tissue (Figure 1B). The gels displayed minimal strain hardening at high frequency $\left(100 \mathrm{rad} \mathrm{s}^{-1}\right)$ and high strain (5\%). Sulfated-HS hydrogels with $3 \mathrm{wt} \%$ of compound 17 had a storage modulus $(0.5-1 \mathrm{kPa})$ appropriate for NSCs cultures and was employed for further studies.

Swelling studies of this hydrogel showed an acceptable swelling ratio of 2.2 over a period of 10 days (Supplementary Figure 1). The microarchitecture observed using SEM and pore size analysis of the SEM images revealed an average pore size of $20.16 \mu \mathrm{m}^{2}$ indicating that the 
material is sufficiently porous to facilitate the migration and proliferation of encapsulated NSCs (Figure 1C).

FGF-2 is a potent mitogen for neural progenitor cells; however, it is highly unstable, and its concentration rapidly declines when incubated at $37{ }^{\circ} \mathrm{C}$, probably due to thermal denaturation, proteolytic digestion and cellular uptake. It has been shown that heparin can prevent degradation and its presence leads to faster cell growth. ${ }^{35,36}$ To evaluate FGF-2 stabilization and retention capacity of the hydrogels, we quantified the cumulative $\%$ release of FGF-2 of hydrogels modified by the sulfated (14) and control oligosaccharide (13) over a period of $72 \mathrm{~h}$. For this experiment, human FGF-2, HS-triazide (13 or 14), and DIBO-4armed PEG polymer (17, $3 \mathrm{wt} \%$ final concentration, 1:1 molar ratio of azide group and DIBO group) were mixed to form a hydrogel, which was overlaid with PBS. At regular time intervals, the PBS was replaced and the concentration of FGF-2 was determined by an enzyme-linked immunosorbent assay (ELISA, Figure 1D). The total amount of FGF-2 released from the sulfated-HS hydrogels was higher than that from the unsulfated-HS hydrogel. The enhanced cumulative release of FGF-2 detected in the sulfated-HS construct is likely due to significantly enhanced protection and lower heat induced degradation of FGF-2 activity in sulfated-HS matrixes when compared to unsulfated-HS matrixes. ${ }^{37-40}$

\section{NSCs Cell Fate in HS-Containing Hydrogel}

We performed a hydrogel contact viability assay in order to evaluate the effects of HS hydrogels on NSC viability. For these assays, NSCs were cultured for $2 \mathrm{~h}$ on a poly-D-lysine coated surface. Subsequently, HS hydrogel components reconstituted in neurobasal media were overlaid on top of the NSC monolayer and allowed to cross-link. After formation of stable hydrogels, hydrogels were overlaid with expansion media and incubated for $24 \mathrm{~h}$ before staining with calcein AM and Hoechst stain. NSC viability was assessed by comparing live cells (green fluorescence) to live or fluorescence) and to bright field images of the NSCs. We observed that the hydrogels formed from $\mathbf{1 4}$ and $\mathbf{1 7}$ did not induce cytotoxicity and that the majority of the encapsulated NSCs were alive $24 \mathrm{~h}$ post encapsulation (94\%) (Figure 2A-E).

In order to investigate the influence of HS oligosaccharides on proliferation, NSCs were encapsulated in the hydrogels modified by the sulfated (14) and control (13) oligosaccharide. Unlike the contact viability assay, where NSCs were cultured in a monolayer, NSCs in these assays were encapsulated by the hydrogel matrix after resuspending the NSC pellet with the HS hydrogel mix. This results in NSCs being distributed throughout the volume of the hydrogel. Hydrogel encapsulated NSCs were cultured in FGF-2 containing media (conditioned media) for $24 \mathrm{~h}$, after which they were cultured in media without FGF-2 (unconditioned media) for an additional 6 days. Next, the rate of proliferation was determined by quantifying total DNA. Both sulfated- and unsulfated-HS hydrogel encapsulated NSCs yielded significantly greater quantities of total DNA, indicating higher proliferation when compared to NSCs cultured under standard 2D culture conditions. Among the hydrogel encapsulated NSCs, those cultured in sulfated-HS matrixes demonstrated significantly greater proliferation when compared to unsulfated-HS controls (Figure 2F), as inferred from the total DNA recovered. Our results also demonstrate 
that FGF-2 deprived NSCs grown under standard 2D culture conditions began differentiating into neural lineage cells within $48 \mathrm{~h}$ postseeding (Supplementary Figure 3) when compared to hydrogel encapsulated NSC, which suggests that hydrogels can efficiently engage endogenously released growth factors and promote NSCs proliferation. Although the cytocompatible cross-linking chemistry and optimum mechanical properties of our synthetic heparin constructs ensure cell viability (Figure 2E), the absence of cell-adhesion peptides in the 3D matrix results in the NSCs exhibiting a rounded morphology, ${ }^{41}$ which is typical of the proliferative state of hydrogel encapsulated NSCs.

Next, we investigated whether the sulfate moieties of the HS disaccharide influences cell differentiation. For this purpose, the relative expression of relevant phenotypic markers of stem cell differentiation was performed by immunocytochemical staining using appropriate antibodies. These studies demonstrated that sulfated-HS oligosaccharide 14, which can stabilize FGF-2, greatly impacted cell differentiation (Figure 3). Thus, NSCs cultured in this hydrogel displayed significantly higher expression of the self-renewal biomarker Sox-1 ( $P<$ $0.001)$ and the astrocytic marker GFAP $(P<0.001)$. Furthermore, we detected a significantly $(\mathrm{P}=0.02)$ lower expression of the oligodendrocyte marker O-4. Although no significant difference in neuronal differentiation as determined by $\beta$-III tubulin was observed, the higher expression of the Sox-1 is indicative of NSCs that are maintaining their undifferentiated state. In addition, we believe higher GFAP expression is indicative of glial lineage NSCs that can differentiate into neurons and glial cells. ${ }^{42}$ Furthermore, the lower expression of the oligodendrocyte marker O-4 indicates NSCs self-renewal and maintenance. The maintenance of self-renewal and proliferative capacity of NSCs is likely due to recruitment and/or stabilization of FGF-2 in the hydrogel containing a HS ligand for this growth factor.

\section{Conclusions}

An important goal in regenerative medicine is to create three dimensional matrixes that resemble properties of the extracellular matrix to guide cell fate. ${ }^{43}$ Integrins are transmembrane receptors that facilitate adhesion of extracellular matrix components such as laminin, collagen, and fibronectin. Peptides derived from these extracellular matrix proteins, such as RGDS, IKVAV, and YIGSR have found wide use in the construction of functional materials for cell adhesion, and their presence can also influence cell fate ${ }^{44,45} \mathrm{HS}$ is also an important component of the extracellular matrix that is involved in growth factor retention and signaling, and efforts have been made to incorporate heparin into biomaterials. 5, 16,30,31 The pleiotropic nature and binding promiscuity of heparin can, however, result in undesired effects. For example, growth differentiation factor 5 (GDF5), which is involved in cartilage/ skeletal formation and homeostasis, is inhibited by heparin. ${ }^{46}$ In addition, heparin can cause hemorrhagic side effects and induce thrombocytopenia. It is derived from animal products exhibiting batch to batch differences and has been contaminated with other sulfated molecules. ${ }^{47,48}$ To address these liabilities of natural derived heparin, we demonstrate here that incorporation of a small and well-defined synthetic HS oligosaccharide into a hydrogel can influence cell fate. In particular, the use of a tailor-made saccharide ligand for FGF-2 greatly increased self-renewal and proliferative capacity of NSCs. 
Chemical synthesis makes it now possible to identify HS oligosaccharides that interact with specific HS-binding proteins. Furthermore, a synthetic approach allows the incorporation of an artificial linker to facilitate controlled attachment of cross-linking functionalities for hydrogel formation. Here, we modified an HS oligosaccharide with a linker having three azido moieties, and a stable hydrogel could be formed by addition of a PEG-derivative modified by four DIBO moieties. We developed DIBO for strain promoted azide-alkyne cycloaddition (SPAAC) ${ }^{49}$ and this reagent reacts spontaneously with azides in the absence of a catalyst and, thus, is attractive for biomedical application. It was found that the presence of a sulfated oligosaccharide did not impede hydrogel formation, and by tuning the concentration of the reaction components, a hydrogel could be formed that has a storage modulus resembling that of neuronal tissue. It is likely that the placement of a HS disaccharide in a pendant fashion within hydrogel scaffolds creates a multivalent display, which augments binding avidity for growth factors owing to the cluster effect, ${ }^{50}$ contributes to thermal stability, and protects against proteolytic cleavage. ${ }^{39,40}$ It is anticipated that, by careful selection of a HS oligosaccharide, it will be possible to control the retention and release of a specific growth factor, which in turn will give greater control over cell fate.

In this study, a HS disaccharide was employed that can bind FGF2 but not induce cell signaling through the formation of a ternary complex with FGFR $1 .{ }^{28}$ Future studies will focus on the incorporation of an HS oligosaccharide that can induce the formation of such a ternary complex, and possible cellular responses will be investigated. Furthermore, PEG was selected as the polymeric material because it is widely used in tissue engineering and approved by FDA for human use. The synthetic approach gives, however, limited control over HS oligosaccharide spacing and valency. Future studies will focus on the use of alternative polymeric backbones, such as dextran or hyaluronic acid, that make it possible to attach HS oligosaccharides at different densities. Such an approach can be combined with the use of other cell-responsive and cell-instructive components such as cell adhesion peptides and protease-cleavable linkers that can promote degradation of a hydrogel.

Traumatic brain injuries and stroke result in significant brain tissue loss and atrophy, which leads to lifelong disabilities and a cost-of-care burden. There is a dire need for therapies for these conditions in order to prevent rampant brain tissue atrophy and promote functional repair. Our future studies will focus on the design of tailored synthetically derived glycomaterials that can better regulate cellular repair cascades in order to facilitate functional recovery following severe brain trauma.

\section{MATERIALS AND METHODS}

\section{Chemical Synthesis}

Preparation of HS-Triazide: General Procedure for Amide Coupling (Scheme 1)

- To the stirring solution of amino compound (10 or 11) in DMSO $(0.5 \mathrm{~mL}$ for $0.05 \mathrm{mmol})$ and DIPEA (4 equiv) at $0{ }^{\circ} \mathrm{C}$ was added compound 12 (2 equiv., in $0.5 \mathrm{~mL}$ of DMSO). The progress of the reaction was monitored by TLC (EtOAc/pyridine $/ \mathrm{H}_{2} \mathrm{O} / \mathrm{AcOH}, 8 / 5 / 3 / 1$, $\mathrm{v} / \mathrm{v} / \mathrm{v} / \mathrm{v}$, or EtOAc/MeOH$\left./ \mathrm{H}_{2} \mathrm{O}, 7 / 2 / 1, \mathrm{v} / \mathrm{v} / \mathrm{v}\right)$. After stirring for $16 \mathrm{~h}$, the reaction mixture was diluted with water $(1.0 \mathrm{~mL})$ and lyophilized. The obtained solid residue was purified by reverse phase chromatography (RP-18 silica gel column, $\mathrm{H}_{2} \mathrm{O} / \mathrm{MeOH}, 9 / 1 \rightarrow 1 / 1$, v/v). The 
appropriate fractions were concentrated in vacuo, and the residue was passed through a column Dowex $50 \times 8 \mathrm{Na}+$ resin $(0.6 \times 5 \mathrm{~cm})$ using $\mathrm{MeOH} / \mathrm{H}_{2} \mathrm{O}, 9 / 1$, as eluent to afford the desired product $(\mathbf{1 3}, 0.038 \mathrm{~g}, 67.9 \% ; \mathbf{1 4}, 0.026 \mathrm{~g}, 71.8 \%)$.

DIBO-Functionalized 4-Armed PEG Polymer (17)-To the stirring mixture of 4armed PEG-amine polymer (15, MW 10K, $0.30 \mathrm{~g}, 0.03 \mathrm{mmol}$, CreativePEGworks) in anhyd. $\mathrm{CH}_{2} \mathrm{Cl}_{2}(3.0 \mathrm{~mL})$ at $0{ }^{\circ} \mathrm{C}$ was added $p$-nitrophenyl carbonate of DIBO $(\mathbf{1 6}, 0.11 \mathrm{~g}, 0.3$ $\mathrm{mmol})$ and $\mathrm{Et}_{3} \mathrm{~N}(0.15 \mathrm{~mL})$. The resulting reaction mixture was left stirring in a melting ice bath for $16 \mathrm{~h}$. After completion of the reaction, confirmed by TLC ( $R_{\mathrm{f}}$ of 0.65 , EtOAc/IPA $\left./ \mathrm{H}_{2} \mathrm{O} / \mathrm{NH}_{4} \mathrm{OH}, 3 / 3 / 2 / 1, \mathrm{v} / \mathrm{v} / \mathrm{v} / \mathrm{v}\right)$, the reaction mixture was concentrated under vacuum to give a yellow oil, which was further purified over a $\mathrm{LH}-20$ column $\left(\mathrm{CH}_{2} \mathrm{Cl}_{2} /\right.$ $\left.\mathrm{CH}_{3} \mathrm{OH}, 1 / 1, \mathrm{v} / \mathrm{v}\right)$ to give the desired compound $\mathbf{1 7}(0.27 \mathrm{~g}, 83.4 \%)$ as a white solid. The detailed synthetic procedures and spectral data of intermediate compounds are provided in the Supporting Information.

Preparation of HS Hydrogels-Stochiometric equivalents of DIBO-4-armed PEG polymer (150 $\mu \mathrm{L}, 10 \mathrm{wt} \%$ in PBS, 17) and unsulfated- or sulfated-HS-triazide (150 $\mu \mathrm{L}, 13$ or 14 in PBS, 1:1 molar ratio of azide group and DIBO group) were mixed by vortexing in a glass vial and left to cross-link for $20 \mathrm{~min}$ at $37{ }^{\circ} \mathrm{C}$. The formation of stable hydrogels was confirmed by the vial-tilting method (Supplementary Figure 1).

\section{Fourier Transform Infrared (FTIR) Spectroscopy}

To determine the degree of azide functional group consumption, FTIR measurements of lyophilized sulfated-HS hydrogel ( 3 wt \%, final concentration of DIBO-4-armed PEG polymer, 17) samples were taken with a Nicolet model 6700 with a grazing angle attenuated total reflectance (GATR) accessory at 64 scans with a $4 \mathrm{~cm}^{-1}$ resolution (Figure 1A).

\section{Rheological Evaluation of HS Hydrogels}

The pendant approach circumvents interference of HS disaccharide in strain promoted cycloaddition between triazide and DIBO polymer. Although the strategic placement of HS has little influence on rheological properties, we nevertheless conducted mechanical characterization on hydrogels that were functionalized using sulfated-HS-triazide. Hydrogels (300 $\mu \mathrm{L}$ each of 2, 3, 4, and $5 \mathrm{wt} \%$ final concentration of DIBO-4-armed PEG polymer, 17) were prepared by mixing an equal volume of $\mathbf{1 7}(150 \mu \mathrm{L})$ and sulfated-HS-triazide $(\mathbf{1 4}, 150$ $\mu \mathrm{L}, 1: 1$ molar ratio of azide group and DIBO group) in a PDMS mold (16 mm diameter and $3 \mathrm{~mm}$ thickness) swelled in PBS for $24 \mathrm{~h}$ at $37^{\circ} \mathrm{C}$. The hydrogels were characterized by isothermal frequency sweep experiments in triplicate from 0.1 to $100 \mathrm{rad}^{-1} \mathrm{~s}^{-1}$ and $5 \%$ strain using a parallel plate rheometer (Anton Paar) (Figure 1B).

\section{Swelling Study of HS Hydrogels}

The swelling ratio of HS hydrogels was measured over a period of 10 days. Sulfated-HS hydrogels (3 wt \%, final concentration of DIBO-functionalized 4-armed PEG polymer, 17, $100 \mu \mathrm{L}$ discs, in triplicate) were prepared on the surface of a $14 \mathrm{~mm}^{2}$ coverslip affixed to glass bottom Petri dishes (In Vitro scientific). The initial weight ( $\left.W_{\mathrm{to}}\right)$ of each hydrogel was obtained by subtracting the weight of glass bottom Petri dishes before and after casting the 
hydrogels. Each hydrogel disc was subsequently overlaid with $100 \mu \mathrm{L}$ of PBS and placed in a tissue culture incubator set at $37{ }^{\circ} \mathrm{C}, 5 \% \mathrm{CO}_{2}$, and $95 \%$ humidity. Swollen hydrogels were weighed $\left(W_{\mathrm{t}}\right)$ immediately after the removal of excess media every $24 \mathrm{~h}$ for 7 days. The hydrogels were overlaid with $100 \mu \mathrm{L}$ of PBS post-weighing. The swelling ratios were calculated by $W_{\mathrm{t}} / W_{\mathrm{to}}$ and plotted (Supplementary Figure 2 ).

\section{Scanning Electron Microscopy (SEM)}

The microarchitecture of HS hydrogels was observed using a Zeiss 1450EP scanning electron microscope (Carl Zeiss). Sulfated-HS hydrogels (3 wt \%, final concentration of DIBO-functionalized 4-armed PEG polymer, 17) were prepared in a polydimethysiloxane (PDMS) mold (16 mm diameter and $3 \mathrm{~mm}$ thickness), swelled in PBS for $24 \mathrm{~h}$ at $37^{\circ} \mathrm{C}$, flash frozen in liquid nitrogen, and then lyophilized for $48 \mathrm{~h}$. The lyophilized gels were mounted on $10 \mathrm{~mm}$ SEM stubs and sputter coated (Structure Probe Inc.) with gold for $60 \mathrm{~s}$ before being imaged under an accelerated voltage of $20 \mathrm{kV}$. Images were acquired at $1000 \times$ and $1500 \times$ magnifications to observe the porosity and structure of the hydrogels. For pore size analysis, 1000× magnified images were processed using ImageJ software (NIH) (Figure $1 \mathrm{C})$.

\section{FGF-2 Retention in HS Hydrogels}

HS hydrogels were cross-linked with human FGF-2, and its cumulateve \% release profile was established using ELISA. DIBO-functionalized 4-armed PEG polymer (25 $\mu \mathrm{L}$ of $6 \mathrm{wt}$ $\%, 17)$ was dispensed into each well of a 96-well plate (in triplicate) followed by the addition of either unsulfated-HS-triazide $(\mathbf{1 3}, 25 \mu \mathrm{L})$ or sulfated-HS-triazide $(\mathbf{1 4}, 25 \mu \mathrm{L})(1: 1$ molar ratio of azide group and DIBO group) containing FGF-2 (10 ng, R\&D Systems, Inc.), mixed by pipetting, and left to cross-link at $37^{\circ} \mathrm{C}$ for $30 \mathrm{~min}$. Upon hydrogel formation, 50 $\mu \mathrm{L}$ of hydrogel was overlaid with $50 \mu \mathrm{L}$ of PBS; the plate was then incubated at $37^{\circ} \mathrm{C}, 5 \%$ $\mathrm{CO}_{2}$, and $95 \%$ humidity. At $6,12,24,36,48$, and $72 \mathrm{~h}$, the overlaid PBS was collected and stored at $-80{ }^{\circ} \mathrm{C}$ and replaced with $50 \mu \mathrm{L}$ of fresh PBS. Due to the nondegradable nature of the HS-PEG hydrogels, the hydrogel bound FGF-2 cannot be retrieved. As a result, the extent of FGF-2 retention was determined as the difference between the initial FGF-2 loaded and the cumulative FGF-2 released. The FGF-2 released by unsulfated-HS and sulfated-HS hydrogels was determined by a human basic FGF Quantikine ELISA kit (R\&D Systems, Inc.) according to the manufacturer's instructions, and the cumulative \% recovery of FGF-2 was plotted (Figure 1D).

\section{NSC Expansion}

Human induced pluripotent cell-derived neural stem cells (HIP-NSCs, MTI-GlobalStem) were expanded on a Geltrex coated plate in expansion media consisting of Neurobasal medium (Life Technologies), B-27 supplement (Life Technologies), MEM nonessential amino acids (Life Technologies), GlutaMAX supplement (Life Technologies), and basic fibroblast growth factor $\left(20 \mathrm{ng} \mathrm{mL}^{-1}, \mathrm{R} \& \mathrm{D}\right.$ Systems, Inc.) and incubated at $37^{\circ} \mathrm{C}, 5 \% \mathrm{CO}$, and $95 \%$ humidity. Cells were fed with expansion media every other day unless passaged or extracted for use in assays. 


\section{Viability Assessment of Hydrogel Overlaid NSCs}

Coverslips affixed to glass bottom Petri dishes (In Vitro scientific) were coated with poly-Dlysine hydrobromide (100 $\mu \mathrm{g} \mathrm{mL}^{-1}$, Sigma-Aldrich) overnight at $37^{\circ} \mathrm{C}$ and washed with PBS before platting $20 \times 10^{3}$ HIP-NSCs. After $1 \mathrm{~h}$, expansion media was aspirated, and sulfated-HS hydrogels ( $3 \mathrm{wt} \%$, final concentration of DIBO-4-armed PEG polymer, 17, 100 $\mu \mathrm{L}$ discs) were prepared on top of the adhered NSCs. Alternatively, NSCs were encapsulated in HS hydrogels by mixing $25 \mu \mathrm{L}$ of 6 wt \% DIBO-functionalized-4-armed PEG polymer (17, containing $\left.20 \times 10^{3} \mathrm{NSCs}\right)$ and sulfated-HS-triazide $(\mathbf{1 4}, 25 \mu \mathrm{L})(1: 1$ molar ratio of azide group and DIBO group) and left to cross-link at $37^{\circ} \mathrm{C}$ for $20 \mathrm{~min}$. The obtained NSC encapsulated hydrogels were overlaid with expansion media and incubated at $37{ }^{\circ} \mathrm{C}, 5 \%$ $\mathrm{CO}_{2}$, and $95 \%$ humidity for $24 \mathrm{~h}$ before being stained with Calcein AM (Thermo Fisher) and Hoechst stain (Thermo Fisher) according to the manufacturer's instructions. Live cells (green fluorescence) were compared to live or dead cells (blue fluorescence) and to bright field images of the cells. Images were analyzed using a Leica DM IRB series microscope (Leica Microsystems, Inc.). Cell viability was assessed using colocalization of Calcein green fluorescence to Hoechst blue fluorescence in 40x images for at least four images per hydrogel sample, using cell colocalization tools associated with Volocity software (PerkinElmer) (Figure 2A-E).

\section{Total DNA Isolation from Hydrogel Encapsulated NSCs}

In order to evaluate the proliferation capacity of the hydrogels and the effect of sulfation on proliferation, total DNA isolated from NSCs grown on a Geltrex coated culture plate was compared with those grown in unsulfated-HS and sulfated-HS hydrogels. $25 \mu \mathrm{L}$ of 6 wt $\%$ DIBO-functionalized-4-armed PEG polymer (17, with $\left.20 \times 10^{3} \mathrm{NSCs}\right)$ was mixed with either unsulfated-HS-triazide $(\mathbf{1 3}, 25 \mu \mathrm{L})$ or sulfated-HS-triazide $(\mathbf{1 4}, 25 \mu \mathrm{L})(1: 1$ molar ratio of azide group and DIBO group) by pipetting and left to cross-link at $37^{\circ} \mathrm{C}$ for $30 \mathrm{~min}$. In addition, a culture plate was Geltrex coated and seeded with NSCs $\left(20 \times 10^{3}\right)$. Culture plates and plates containing HS hydrogels were overlaid with $2.0 \mathrm{~mL}$ of expansion media and incubated at $37{ }^{\circ} \mathrm{C}, 5 \% \mathrm{CO}_{2}$, and $95 \%$ humidity. After $24 \mathrm{~h}$, expansion media was replaced with basal media (expansion media without FGF-2), and NSC incubation was continued in a FGF-2 deprived condition. After 7 days, the total amount of DNA present in NSCs grown on Geltrex coated culture plates (at time zero, $T_{0}$ and time day $7, \mathrm{~T}_{7}$ ) and unsulfated-HS and sulfated-HS hydrogels was determined by a Zymoclean gel DNA recovery kit (Zymo research corp.) according to the manufacturer's instructions, and the total DNA isolated was plotted (Figure 2F).

\section{Immunocytochemistry}

NSCs encapsulated in unsulfated-HS (two groups, in triplicate) and sulfated-HS (two groups, in triplicate) hydrogels were fixed with $4 \%$ paraformaldehyde containing $0.4 \mathrm{M}$ sucrose in PBS. After 20 min, the hydrogels were rinsed thrice with PBS and permeabilized in blocking buffer (PBS containing 4\% goat serum and 0.5\% Triton-X100) for $1 \mathrm{~h}$. Subsequently, the group-1 hydrogels (both unsulfated- and sulfated-HS hydrogels) were incubated at $4{ }^{\circ} \mathrm{C}$ with blocking buffer containing primary antibodies (at dilutions of 1:500) against $\beta$-III tubulin (Millipore), a neuronal cytoskeletal marker; O-4 (R\&D Systems, Inc.), 
an oligodendrocyte marker; glial fibrillary acidic protein (GFAP, R\&D Systems, Inc.), an astrocyte marker. The group-2 hydrogels (both unsulfated- and sulfated-HS hydrogels) were incubated with a neural stem cell marker: Sox-1 (R\&D Systems, Inc.). After 16 h, the hydrogels were rinsed thrice with PBS and incubated with blocking buffer again for $1 \mathrm{~h}$ followed by the addition of appropriate AlexaFluor 488 (Life Technologies), AlexaFluor 555 (Life Technologies), and Cy5 (Life Technologies) labeled secondary antibodies and incubation for $1 \mathrm{~h}$. After rinsing hydrogels thrice with PBS, a nuclear stain (NucBlue, Life Technologies, CA) was added to the hydrogels; they were then incubated for $5 \mathrm{~min}$ and rinsed thrice with PBS. The hydrogels were subsequently mounted with fluoromount-G (SouthernBiotech) and a coverslip was placed on top the next day. NSCs were imaged using a Leica DM IRB series microscope (Leica Microsystems, Inc.). Representative highmagnification images (15 in total, from three replicates) of unsulfated-HS and sulfated-HS hydrogels were analyzed using cell population tools in Volocity software (PerkinElmer) (Figure 3). The Manders overlap coefficient was used to measure the degree of colocalization between fluorescent images, as described previously. ${ }^{51}$ Each separate signal intensity was quantified against the DAPI signal to provide the percentages of cells positive for markers found in the FITC, TRITC, or Cy5 channels.

\section{Statistical Analysis}

All statistical analyses were performed using a one-way analysis of variance (ANOVA) for significance with appropriate posthoc tests using GraphPad Prism or SigmaPlot software. Direct mean comparisons were evaluated using a Student's t-test. All studies were performed in triplicate at the minimum. Statistical differences observed between groups are represented by ns indicating not significant, **** indicating $P<0.001$, and ** indicating $P<$ 0.01 .

\section{Supplementary Material}

Refer to Web version on PubMed Central for supplementary material.

\section{ACKNOWLEDGMENTS}

This research was supported by the National Institute of General Medicine (NIGMS; Research Resource for Integrated Glycotechnology P41GM103390 to G.-J.B.) and the National Institute of Neurological Disorders and Stroke (NINDS; R01NS099596 to L.K.) of the National Institutes of Health (NIH).

\section{REFERENCES}

(1). Peppas NA, Hilt JZ, Khademhosseini A, and Langer R (2006) Hydrogels in Biology and Medicine: From Molecular Principles to Bionanotechnology. Adv. Mater 18, 1345-1360.

(2). Slaughter BV, Khurshid SS, Fisher OZ, Khademhosseini A, and Peppas NA (2009) Hydrogels in Regenerative Medicine. Adv. Mater 21, 3307-3329. [PubMed: 20882499]

(3). Seliktar D (2012) Designing Cell-Compatible Hydrogels for Biomedical Applications. Science 336, 1124-1128. [PubMed: 22654050]

(4). Ventre M, and Netti PA (2016) Engineering Cell Instructive Materials to Control Cell Fate and Functions through Material Cues and Surface Patterning. ACS Appl Mater. Interfaces 8, 1489614908. [PubMed: 26693600] 
(5). Freudenberg U, Liang Y, Kiick KL, and Werner C (2016) Glycosaminoglycan-Based Biohybrid Hydrogels: A Sweet and Smart Choice for Multifunctional Biomaterials. Adv. Mater 28, 88618891. [PubMed: 27461855]

(6). Bishop JR, Schuksz M, and Esko JD (2007) Heparan Sulphate Proteoglycans Fine-tune Mammalian Physiology. Nature 446, 1030-1037. [PubMed: 17460664]

(7). Sarrazin S, Lamanna WC, and Esko JD (2011) Heparan Sulfate Proteoglycans. Cold Spring Harbor Perspect. Biol 3, 1-33.

(8). Turnbull J, Powell A, and Guimond S (2001) Heparan sulfate: Decoding a Dynamic Multifunctional Cell Regulator. Trends Cell Biol. 11, 75-82. [PubMed: 11166215]

(9). Kamhi E, Joo EJ, Dordick JS, and Linhardt RJ (2013) Glycosaminoglycans in Infectious Disease. Biol. Rev 88, 928-943. [PubMed: 23551941]

(10). García B, Merayo-Lloves J, Martin C, Alcalde I, Quirós LM, and Vazquez F (2016) Surface Proteoglycans as Mediators in Bacterial Pathogens Infections. Front. Microbiol 7, 220. [PubMed: 26941735]

(11). Kraushaar DC, Dalton S, and Wang L (2013) Heparan sulfate: a Key Regulator of Embryonic Stem Cell Fate. Biol. Chem 394, 741-751. [PubMed: 23370908]

(12). Yu C, Griffiths LR, and Haupt LM (2017) Exploiting Heparan Sulfate Proteoglycans in Human Neurogenesis-Controlling Lineage Specification and Fate. Front. Integr. Neurosci 11, 28. [PubMed: 29089873]

(13). Joung YK, Bae JW, and Park KD (2008) Controlled Release of Heparin-binding Growth Factors using Heparin-containing Particulate Systems for Tissue Regeneration. Expert Opin. Drug Delivery 5, 1173-1184.

(14). Nillesen STM, Geutjes PJ, Wismans R, Schalkwijk J, Daamen WF, and van Kuppevelt TH (2007) Increased Angiogenesis and Blood Vessel Maturation in Acellular Collagen-Heparin Scaffolds containing both FGF2 and VEGF. Biomaterials 28, 1123-1131. [PubMed: 17113636]

(15). Bhakta G, Rai B, Lim ZXH, Hui JH, Stein GS, van Wijnen AJ, Nurcombe V, Prestwich GD, and Cool SM (2012) Hyaluronic Acid-based Hydrogels Functionalized with Heparin that Support Controlled Release of Bioactive BMP-2. Biomaterials 33, 6113-6122. [PubMed: 22687758]

(16). Ayerst BI, Merry CLR, and Day AJ (2017) The Good the Bad and the Ugly of Glycosaminoglycans in Tissue Engineering Applications. Pharmaceuticals 10, 54.

(17). Freudenberg U, Zieris A, Chwalek K, Tsurkan MV, Maitz MF, Atallah P, Levental KR, Eming SA, and Werner C (2015) Heparin Desulfation Modulates VEGF Release and Angiogenesis in Diabetic Wounds. J. Controlled Release 220, 79-88.

(18). Murali S, Rai B, Dombrowski C, Lee JLJ, Lim ZXH, Bramono DS, Ling L, Bell T, Hinkley S, Nathan SS, Hui JH, Wong HK, Nurcombe V, and Cool SM (2013) Affinity-Selected Heparan Sulfate for Bone Repair. Biomaterials 34, 5594-5605. [PubMed: 23632323]

(19). Mende M, Bednarek C, Wawryszyn M, Sauter P, Biskup MB, Schepers U, and Bräse S (2016) Chemical Synthesis of Glycosaminoglycans. Chem. Rev 116, 8193-8255. [PubMed: 27410264]

(20). Peterson S, Frick A, and Liu J (2009) Design of Biologically Active Heparan Sulfate and Heparin using an Enzyme-based Approach. Nat. Prod. Rep 26, 610-627. [PubMed: 19387498]

(21). Hu Y-P, Zhong Y-Q, Chen Z-G, Chen C-Y, Shi Z, Zulueta MML, Ku C-C, Lee P-Y, Wang C-C, and Hung S-C (2012) Divergent Synthesis of 48 Heparan Sulfate-Based Disaccharides and Probing the Specific Sugar-Fibroblast Growth Factor-1 Interaction. J. Am. Chem. Soc 134, 20722-20727. [PubMed: 23240683]

(22). Zong C, Venot A, Li X, Lu W, Xiao W, Wilkes J-SL, Salanga CL, Handel TM, Wang L, Wolfert MA, and Boons G-J (2017) Heparan Sulfate Microarray Reveals that Heparan Sulfate-Protein Binding Exhibits Different Ligand Requirements. J. Am. Chem. Soc 139, 9534-9543. [PubMed: 28651046]

(23). Yang J, Hsieh P-H, Liu X, Zhou W, Zhang X, Zhao J, Xu Y, Zhang F, Linhardt RJ, and Liu J (2017) Construction and Characterisation of a Heparan Sulphate Heptasaccharide Microarray.Chem. Commun 53, 1743-1746.

(24). de Paz JL, Noti C, Böhm F, Werner S, and Seeberger PH (2007) Potentiation of Fibroblast Growth Factor Activity by Synthetic Heparin Oligosaccharide Glycodendrimers. Chem. Biol 14, 879-887. [PubMed: 17719487] 
(25). Sheng GJ, Oh YI, Chang S-K, and Hsieh-Wilson LC (2013) Tunable Heparan Sulfate Mimetics for Modulating Chemokine Activity. J. Am. Chem. Soc 135, 10898-10901. [PubMed: 23879859]

(26). Huang ML, Smith RAA, Trieger GW, and Godula K (2014) Glycocalyx Remodeling with Proteoglycan Mimetics Promotes Neural Specification in Embryonic Stem Cells. J. Am. Chem. Soc 136, 10565-10568. [PubMed: 25019314]

(27). Loka RS, Yu F, Sletten ET, and Nguyen HM (2017) Design, Synthesis, and Evaluation of Heparan Sulfate Mimicking Glycopolymers for Inhibiting Heparanase Activity. Chem. Commun 53, 9163-9166.

(28). Li Y-C, Ho IH, Ku C-C, Zhong Y-Q, Hu Y-P, Chen Z-G, Chen C-Y, Lin W-C, Zulueta MML, Hung S-C, Lin M-G, Wang C-C, and Hsiao C-D (2014) Interactions that Influence the Binding of Synthetic Heparan Sulfate based Disaccharides to Fibroblast Growth Factor-2. ACS Chem. Biol 9, 1712-1717. [PubMed: 24959968]

(29). Martino G, and Pluchino S (2006) The Therapeutic Potential of Neural Stem Cells. Nat. Rev. Neurosci. 7, 395-406. [PubMed: 16760919]

(30). Sakiyama-Elbert SE (2014) Incorporation of Heparin into Biomaterials. Acta Biomater. 10, 1581-1587. [PubMed: 24021232]

(31). Liang Y, and Kiick KL (2014) Heparin-Functionalized Polymeric Biomaterials in Tissue Engineering and Drug Delivery Applications. Acta Biomater. 10, 1588-1600. [PubMed: 23911941]

(32). Zheng J, Smith Callahan LA, Hao J, Guo K, Wesdemiotis C, Weiss RA, and Becker ML (2012) Strain-Promoted Cross-Linking of PEG-Based Hydrogels via Copper-Free Cycloaddition. ACS Macro Lett. 1, 1071-1073. [PubMed: 23205321]

(33). Arungundram S, Al-Mafraji K, Asong J, Leach FE, Amster IJ, Venot A, Turnbull JE, and Boons G-J (2009) Modular Synthesis of Heparan Sulfate Oligosaccharides for Structure-Activity Relationship Studies. J. Am. Chem. Soc 131, 17394-17405. [PubMed: 19904943]

(34). Song H-O, Lee B, Bhusal RP, Park B, Yu K, Chong C-K, Cho P, Kim SY, Kim HS, and Park H (2012) Development of a Novel Fluorophore for Real-Time Biomonitoring System. PLoS One 7, No. e48459.

(35). Caldwell MA, Garcion E, Ter Borg MG, He X, and Svendsen CN (2004) Heparin Stabilizes FGF-2 and Modulates Striatal Precursor Cell Behavior in Response to EGF. Exp. Neurol 188, 408-420. [PubMed: 15246840]

(36). Chen G, Gulbranson DR, Yu P, Hou Z, and Thomson JA (2012) Thermal Stability of Fibroblast Growth Factor Protein Is a Determinant Factor in Regulating Self-Renewal, Differentiation, and Reprogramming in Human Pluripotent Stem Cells. Stem Cells 30, 623-630. [PubMed: 22213113]

(37). Gospodarowicz D, and Cheng J (1986) Heparin Protects Basic and Acidic FGF from Inactivation. J. Cell. Physiol 128, 475-484. [PubMed: 3528177]

(38). Habuchi H, Suzuki S, Saito T, Tamura T, Harada T, Yoshida K, and Kimata K (1992) Structure of a Heparan Sulphate Oligosaccharide that Binds to Basic Fibroblast Growth Factor. Biochem. J 285, 805-813. [PubMed: 1497618]

(39). Damon DH, Lobb RR, D'Amore PA, and Wagner JA (1989) Heparin Potentiates the Action of Acidic Fibroblast Growth Factor by Prolonging its Biological Half-life. J. Cell. Physiol 138, 221226. [PubMed: 2465300]

(40). Damon DH, Halegoua S, D’Amore P, and Wagner JA (1992) Rapid Fibroblast Growth Factorinduced Increases in Protein Phosphorylation and Ornithine Decarboxylase Activity: Regulation by Heparin and Comparison to Nerve Growth Factor-induced Increases. Exp. Cell Res 201, 154159. [PubMed: 1351851]

(41). Karumbaiah L, Enam SF, Brown AC, Saxena T, Betancur MI, Barker TH, and Bellamkonda RV (2015) Chondroitin Sulfate Glycosaminoglycan Hydrogels Create Endogenous Niches for Neural Stem Cells. Bioconjugate Chem. 26, 2336-2349.

(42). Kriegstein A, and Alvarez-Buylla A (2009) The Glial Nature of Embryonic and Adult Neural Stem Cells. Annu. Rev. Neurosci 32, 149-184. [PubMed: 19555289]

(43). Liu X, Holzwarth JM, and Ma PX (2012) Functionalized Synthetic Biodegradable Polymer Scaffolds for Tissue Engineering. Macromol. Biosci 12, 911-919. [PubMed: 22396193] 
(44). Streuli CH (2009) Integrins and Cell-fate Determination. J. Cell Sci 122, 171-177. [PubMed: 19118209]

(45). Huettner N, Dargaville TR, and Forget A (2018) Discovering Cell-Adhesion Peptides in Tissue Engineering: Beyond RGD. Trends Biotechnol. 36, 372-383. [PubMed: 29422411]

(46). Ayerst BI, Smith RAA, Nurcombe V, Day AJ, Merry CLR, and Cool SM (2017) Growth Differentiation Factor 5-Mediated Enhancement of Chondrocyte Phenotype Is Inhibited by Heparin: Implications for the Use of Heparin in the Clinic and in Tissue Engineering Applications. Tissue Eng. Part A 23, 275-292. [PubMed: 27899064]

(47). Blossom DB, Kallen AJ, Patel PR, Elward A, Robinson L, Gao G, Langer R, Perkins KM, Jaeger JL, Kurkjian KM, Jones M, Schillie SF, Shehab N, Ketterer D, Venkataraman G, Kishimoto TK, Shriver Z, McMahon AW, Austen KF, Kozlowski S, Srinivasan A, Turabelidze G, Gould CV, Arduino MJ, and Sasisekharan R (2008) Outbreak of Adverse Reactions Associated with Contaminated Heparin. N. Engl. J. Med 359, 2674-2684. [PubMed: 19052120]

(48). Guerrini M, Beccati D, Shriver Z, Naggi A, Viswanathan K, Bisio A, Capila I, Lansing JC, Guglieri S, Fraser B, Al- Hakim A, Gunay NS, Zhang Z, Robinson L, Buhse L, Nasr M, Woodcock J, Langer R, Venkataraman G, Linhardt RJ, Casu B, Torri G, and Sasisekharan R (2008) Oversulfated Chondroitin Sulfate is a Contaminant inHeparin Associated with Adverse Clinical Events. Nat. Biotechnol 26, 669-675. [PubMed: 18437154]

(49). Ning X, Guo J, Wolfert MA, and Boons G-J (2008) Visualizing Metabolically Labeled Glycoconjugates of Living Cells by Copper-Free and Fast Huisgen Cycloadditions. Angew. Chem., Int. Ed 47, 2253-2255.

(50). Mammen M, Choi S-K, and Whitesides GM (1998) Polyvalent Interactions in Biological Systems: Implications for Design and Use of Multivalent Ligands and Inhibitors. Angew. Chem., Int. Ed 37, 2754-2794.

(51). Betancur MI, Mason HD, Alvarado-Velez M, Holmes PV, Bellamkonda RV, and Karumbaiah L (2017) Chondroitin Sulfate Glycosaminoglycan Matrices Promote Neural Stem Cell Maintenance and Neuroprotection Post-Traumatic Brain Injury. ACS Biomater. Sci. Eng 3, 420-430.

[PubMed: 29744379] 
A

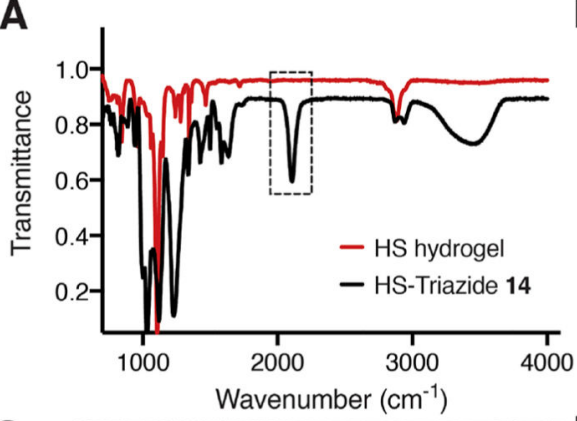

C
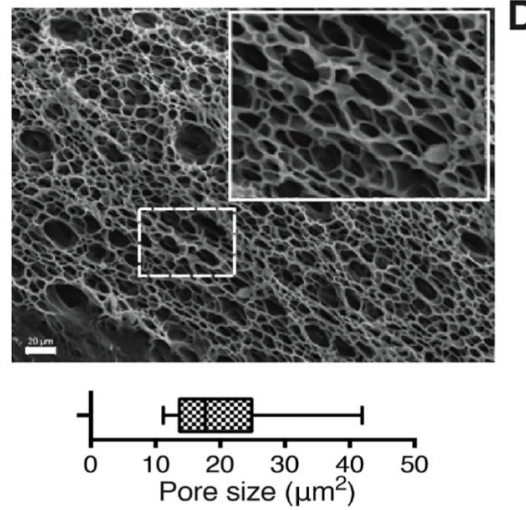

B

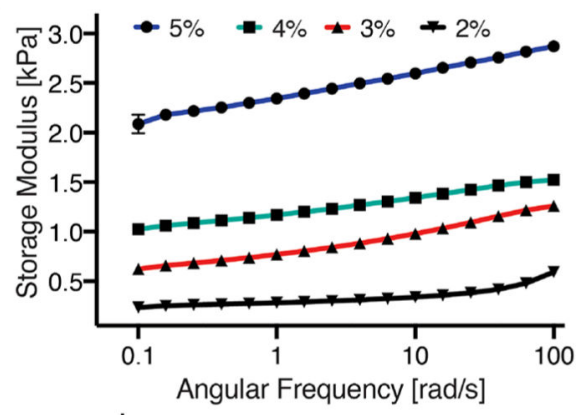

D

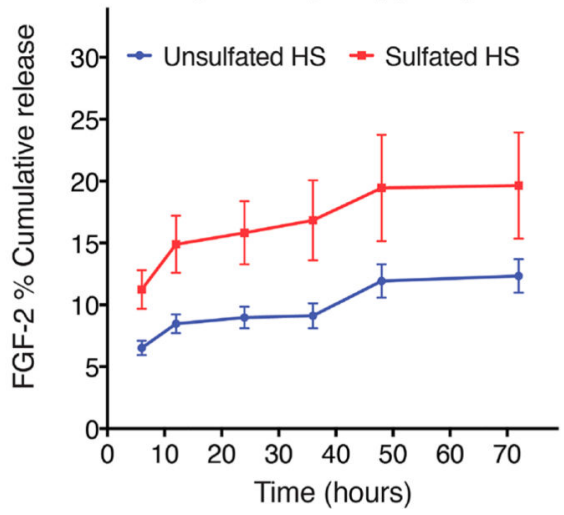

Figure 1.

Physio-mechanical characterization of HS hydrogels. (A) An overlay of FTIR spectra of sulfated-HS-triazide (14) and lyophilized sulfated-HS hydrogel showing the consumption of azide $\left(2095 \mathrm{~cm}^{-1}\right)$. (B) Storage moduli of 2, 3, 4, and $5 \mathrm{wt} \%$ sulfated-HS hydrogels over a frequency range of 0.1 to $100 \mathrm{rad} \mathrm{s}^{-1}$ at a constant strain of $5 \%$ at $25{ }^{\circ} \mathrm{C}$. (C) Scanning electron micrograph (SEM) of a lyophilized $3 \mathrm{wt} \%$ sulfated-HS hydrogel at magnification of 500x (inset represents a magnified image of the dashed box); pore size analysis of the SEM images displays an average pore size of $20.16 \mu \mathrm{m}^{2}$. (D) Cumulative $\%$ release of FGF-2 encapsulated in sulfated-HS and unsulfated-HS hydrogels determined by ELISAs. 

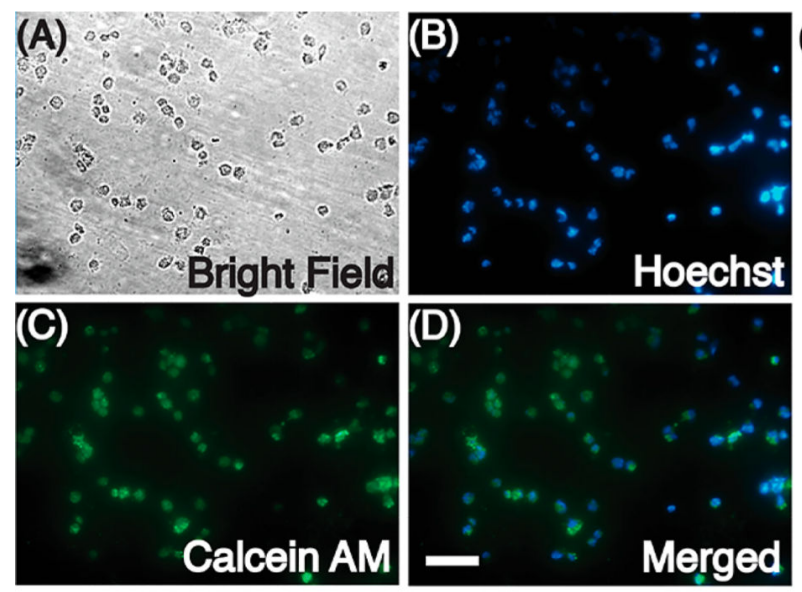

(E)

(F)

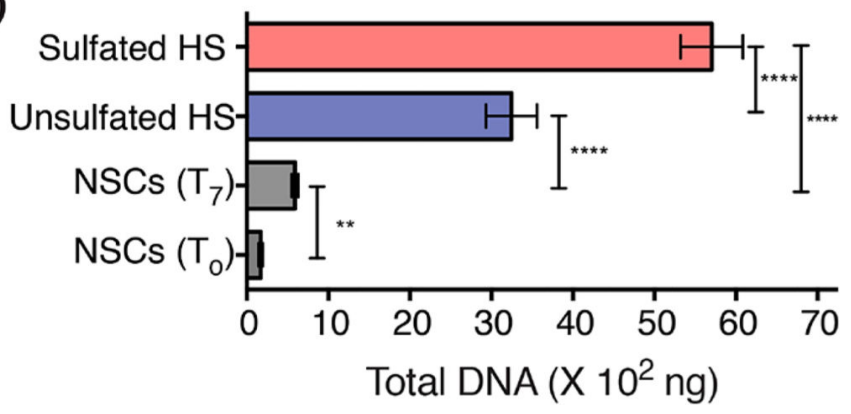

Figure 2.

Cytocompatibility and proliferation of NSCs encapsulated in HS hydrogels. NSCs were stained for nuclei (Hoechst) and live cell (Calcein AM) detection after culturing for $24 \mathrm{~h}$. A bright field image and an overlay of these images are also presented (A-D). Scale, $50 \mu \mathrm{m}$. (E) Viability of NSCs. (F) Total isolated DNA from NSCs grown on Geltrex coated culture plates ( $T_{0}$, day 0 and $T_{7}$, day 7) and from NSCs encapsulated in the sulfated (14)-HS and unsulfated (13, control)-HS hydrogel. Statistical differences observed between groups are represented by $* * * *$ indicating $P<0.001$ and ** indicating $P<0.01$. 


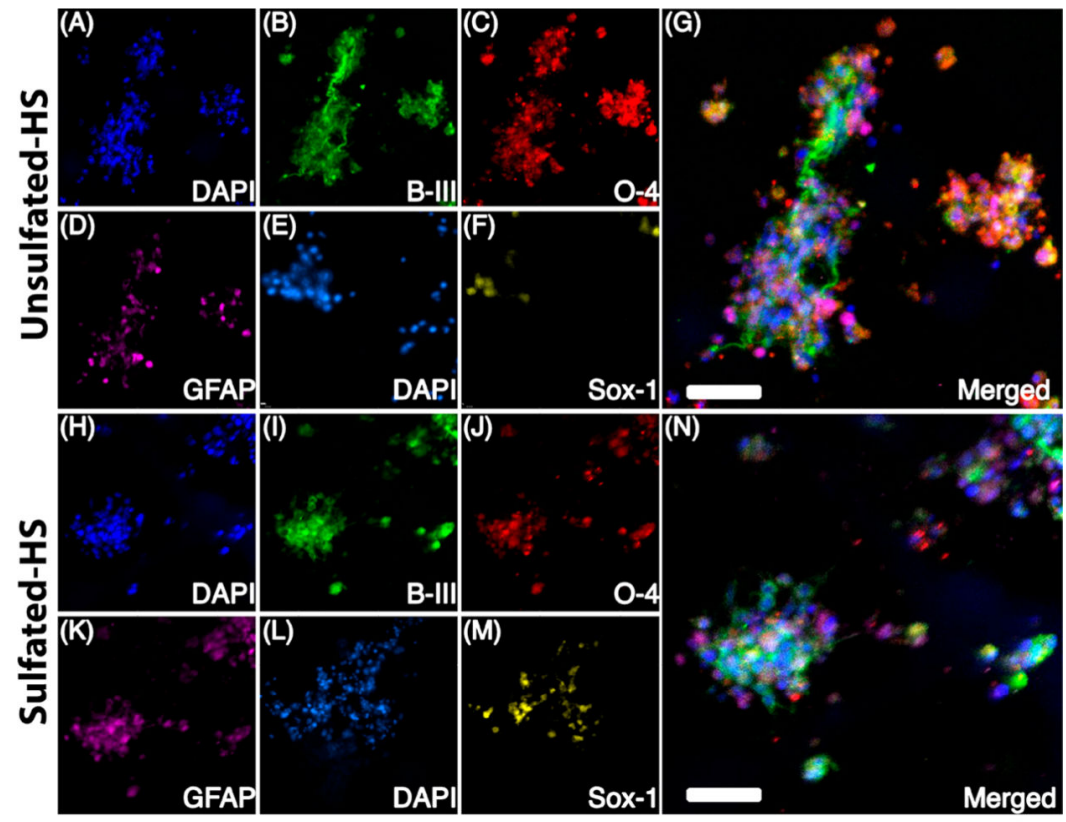

(0)

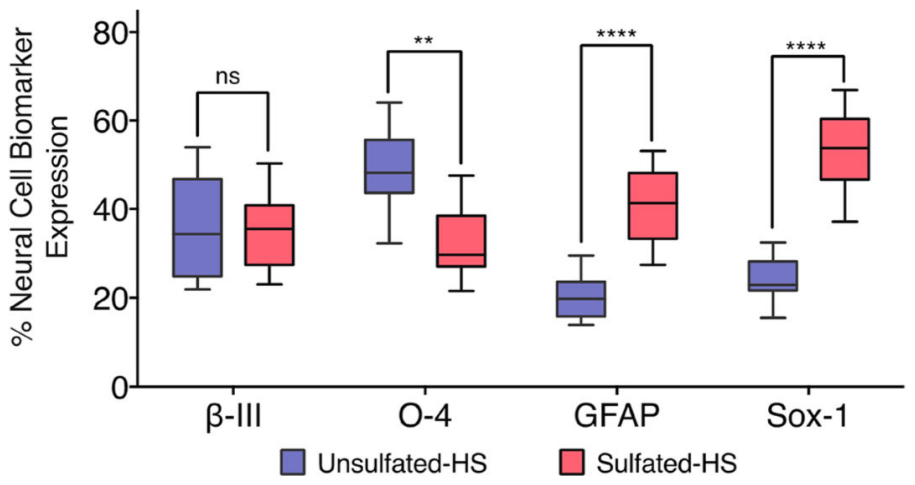

Figure 3.

Immunocytochemistry results of NSCs encapsulated in HS hydrogels. (A-G) A representative image (Z-stack) of NSCs encapsulated in a $3 \mathrm{wt} \%$ unsulfated-HS hydrogel conditioned for $24 \mathrm{~h}$ with FGF-2 and cultured for 6 days without FGF-2; Group-1 unsulfated-HS hydrogels were stained for nuclei, neuronal, oligodendrocyte, and astrocyte markers, represented by DAPI (A), $\beta$-III tubulin (B), O-4 (C), and GFAP (D), respectively. An overlay of these images (A-D) is also presented (G); Group-2 unsulfated-HS hydrogels were stained for nuclei and stem cell marker, represented by DAPI (E) and Sox-1 (F), respectively. An overlay of these images (E, F) is presented in Supplementary Figure 4; $(\mathrm{H}-$ N) NSCs encapsulated in a $3 \mathrm{wt} \%$ sulfated-HS hydrogel conditioned for $24 \mathrm{~h}$ with FGF-2 and cultured for 6 days without additional FGF-2. Group-1 sulfated-HS hydrogels were stained for nuclei, neuronal, oligodendrocyte, and astrocyte markers and are represented by DAPI (H), $\beta$-III tubulin (I), O-4 (J), and GFAP (K), respectively. An overlay of these images $(\mathrm{H}-\mathrm{K})$ is also presented $(\mathrm{N})$; Group-2 sulfated-HS hydrogels were stained for nuclei and stem cell marker, represented by DAPI (L) and Sox-1 (M), respectively. An overlay of these images (L, M) is presented in Supplementary Figure 4; scale, $20 \mu \mathrm{m}$. (O) Quantification of markers $\beta$-III tubulin, O-4, GFAP, and Sox-1 expression in NSCs encapsulated in 
unsulfated-HS and sulfated-HS hydrogel. Statistical differences observed between groups are represented by ns indicating not significant, $* * * *$ indicating $\mathrm{P}<0.001$, and $* *$ indicating $P<0.01$. 
A
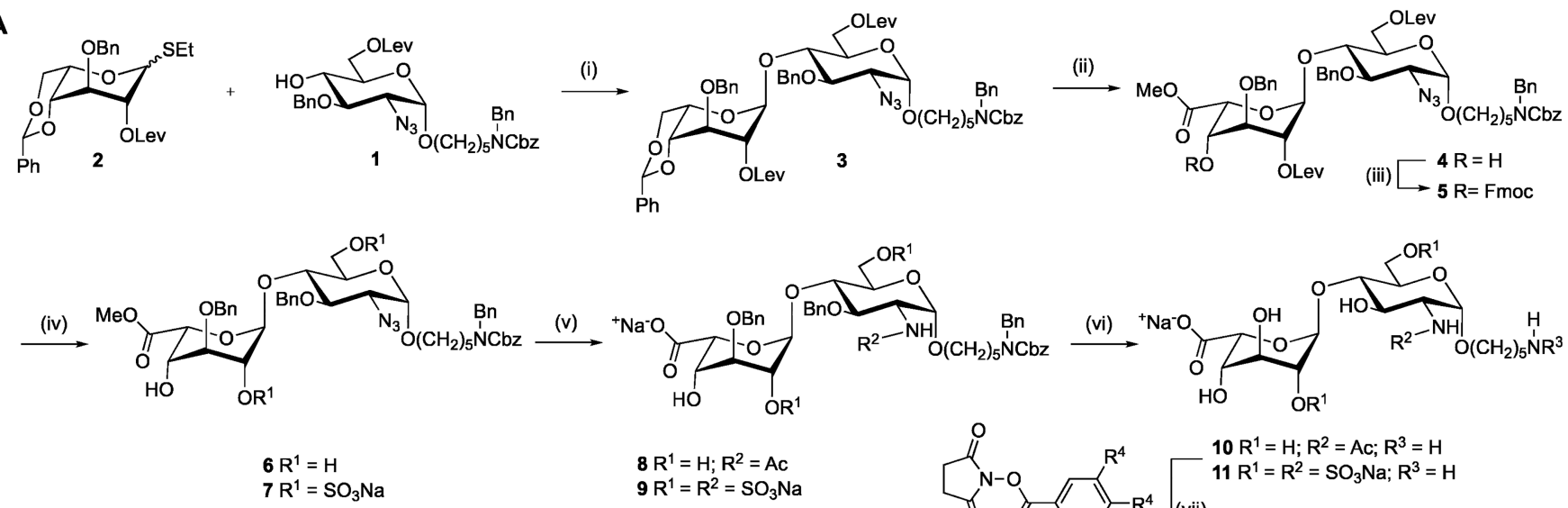

\section{B}
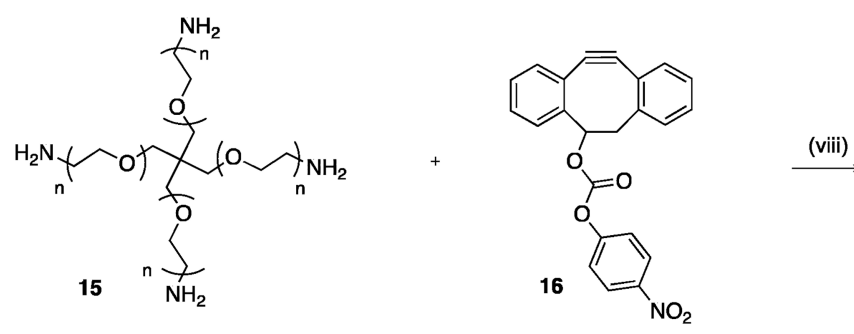

Scheme 1. Chemical Synthesis of HS Hydrogel Precursors ${ }^{a}$

a(A) Unsulfated-HS-triazide (13) and sulfated-HS-triazide (14); (B) DIBO-4-armed PEG polymer (17). Reagents and conditions: (i) NIS, TMSOTf, DCM, $-20{ }^{\circ} \mathrm{C}, 0.5 \mathrm{~h}$; (ii) (a) DCM/TFA $/ \mathrm{H}_{2} \mathrm{O}, 0{ }^{\circ} \mathrm{C}$ to rt, $1 \mathrm{~h}$; (b) TEMPO, BAIB, DCM/ $\mathrm{H}_{2} \mathrm{O}, 1 \mathrm{~h}$; (c) $\mathrm{CH}_{2} \mathrm{~N}_{2}$, THF, $0.5 \mathrm{~h}$; (iii) FmocCl, pyridine, DMAP (cat.), 2 h; (iv) (a) hydrazine acetate, EtOH/toluene (2/1, v/v), $2 \mathrm{~h}$; (b) $\mathrm{SO}_{3}$.pyridine complex, DMF, 8 h; (c) $\mathrm{Et}_{3} \mathrm{~N} / \mathrm{MeOH}(1 / 1$, v/v), $0.5 \mathrm{~h}$; for 6, only step a on 4; for 7, steps a, b, and c on 5; (v) (a) $1.0 \mathrm{M}$ aq. $\mathrm{LiOH}$, aq. $\mathrm{H}_{2} \mathrm{O}_{2}(50 \%), 8 \mathrm{~h}$ then $\mathrm{pH} \sim 14$ with 4.0 M NaOH, 16 h; (b) 1.0 $\mathrm{M} \mathrm{PMe}_{3}$ in THF, $\mathrm{NaOH}, 1 \mathrm{~h}$; (c) $\mathrm{Ac}_{2} \mathrm{O}, \mathrm{NEt}_{3}, \mathrm{MeOH}$; (d) $\mathrm{SO}_{3}$-pyridine complex, $\mathrm{MeOH}, \mathrm{Et}_{3} \mathrm{~N}, 0.1 \mathrm{M} \mathrm{NaOH}, 16 \mathrm{~h}$; for 8, steps a, b, and c on 6; for 9, stepd a, b, and d on 7; (vi) (a) $\mathrm{Pd} / \mathrm{C}, \mathrm{H}_{2}$ (atm.), ${ }^{\mathrm{t}} \mathrm{BuOH} / \mathrm{H}_{2} \mathrm{O}(1 / 1, \mathrm{v} / \mathrm{v}), 2 \mathrm{~h}$; (b) $\mathrm{Pd}(\mathrm{OH})_{2} / \mathrm{C}$, $\mathrm{H}_{2}$ (atm.), ${ }^{\mathrm{t}} \mathrm{BuOH} / \mathrm{H}_{2} \mathrm{O}$ (1/1, v/v), $16 \mathrm{~h}, 10$ from 8 and 11 from 9; (vii) DIPEA, DMSO, $0{ }^{\circ} \mathrm{C}$ to rt, $16 \mathrm{~h}, 13$ from 10 and 14 from 11 ; (viii) $\mathrm{Et}_{3} \mathrm{~N}, \mathrm{DCM}, 0{ }^{\circ} \mathrm{C}$ to $16 \mathrm{~h}$. 